\title{
HPV Infection in Esophageal Squamous Cell Carcinoma and Its Relationship to the Prognosis of Patients in Northern China
}

\author{
Fangli Cao, ${ }^{1,2}$ Hui Han, ${ }^{2}$ Fang Zhang, ${ }^{3}$ Baozhong Wang, ${ }^{2}$ Wei Ma, ${ }^{4}$ Yanwen Wang, ${ }^{2}$ \\ Guiming Sun, ${ }^{2}$ Miao Shi, ${ }^{5}$ Yubo Ren, ${ }^{6}$ and Yufeng Cheng ${ }^{1}$ \\ ${ }^{1}$ Department of Radiation Oncology, Qilu Hospital of Shandong University, No. 44 Wenhua Xi Road, Jinan 250012, China \\ ${ }^{2}$ Department of Oncology, Liaocheng People's Hospital, Liaocheng 252000, China \\ ${ }^{3}$ Department of Oncology, The First Hospital of Zibo, Zibo 255000, China \\ ${ }^{4}$ Department of Radiation Oncology, Cancer Hospital, General Hospital of Ningxia Medical University, Yinchuan 750000, China \\ ${ }^{5}$ Department of Ultrasound, Liaocheng People's Hospital, Liaocheng 252000, China \\ ${ }^{6}$ Department of Pathology, Liaocheng People's Hospital, Liaocheng 252000, China
}

Correspondence should be addressed to Yufeng Cheng; qilucyf@126.com

Received 15 September 2013; Accepted 5 December 2013; Published 12 January 2014

Academic Editors: D. H. Dinh and J. Hofmann

Copyright (C) 2014 Fangli Cao et al. This is an open access article distributed under the Creative Commons Attribution License, which permits unrestricted use, distribution, and reproduction in any medium, provided the original work is properly cited.

Purpose. Human papillomavirus (HPV) as a risk factor for esophageal squamous cell carcinoma (ESCC) has previously been studied, but importance of HPV status in ESCC for prognosis is less clear. Methods. A total of 105 specimens with ESCC were tested by in situ hybridization for HPV 16/18 and immunohistochemistry for p16 expression. The 5-year overall survival (OS) and progression-free survival were calculated in relation to these markers and the Cox proportional hazards model was used to determine the hazard ratio (HR) of variables in univariate and multivariate analysis. Results. HPV was detected in 27.6\% (29) of the 105 patients with ESCC, and all positive cases were HPV-16. Twenty-five (86.2\%) of the $29 \mathrm{HPV}$-positive tumors were stained positive for p16. HPV infected patients had better 5 -year rates of OS (65.9\% versus $43.4 \%$ among patients with HPV-negative tumors; $P=0.002$ by the log-rank test) and had a $63 \%$ reduction in the risk of death (adjusted $\mathrm{HR}=0.37,95 \% \mathrm{CI}=0.16$ to 0.82 , and $P=0.01$ ). Conclusions. HPV infection may be one of many factors contributing to the development of ESCC and tumor HPV status is an independent prognostic factor for survival among patients with ESCC.

\section{Introduction}

Esophageal cancer is the eighth most common cancer and the sixth most common cause of death from cancer, worldwide $[1,2]$. Once developed, esophageal cancer usually rapidly invades surrounding tissues and lymph nodes [3]. Due to the absence of early symptoms, invasiveness of the disease, and its late diagnosis, it is generally associated with a poor prognosis [4]. Despite increasing rates of esophageal adenocarcinoma in many western countries, esophageal squamous cell carcinoma (ESCC) remains the dominant histological type of esophageal cancer worldwide. ESCC is still the main cancer burden and the fourth most common cause of death in China [5], especially northern China [6], and thus is the focus of this study.
The etiology of ESCC remains unclear, and epidemiological studies suggest that tobacco smoking, heavy alcohol drinking, micronutrient deficiency $[7,8]$, and dietary carcinogen exposure may cause the malignancy. Infectious agents have been implicated, as either direct carcinogens or promoters. In particular, human papillomavirus (HPV) has been postulated as a possible cause of ESCC [9]. HPV infection in esophageal cancer was first suggested in 1982 based on histological observations [10]. Subsequent studies using various methods have confirmed the presence of HPV in $\operatorname{ESCC}[9,11]$.

HPV types 16 and 18 are known to cause the majority of squamous cell carcinomas of the cervix [12-15] and are strongly associated with cancers of the head and neck, particularly the oropharynx [16-18]. The viral oncogene 
products E6 and E7 play a key role in HPV-associated carcinogenesis, abrogating p53 and retinoblastoma tumor suppressor functions, respectively $[19,20]$. E7 binds to and degrades $\mathrm{Rb}$, releasing E2F, leading to $\mathrm{p} 16^{\mathrm{INK} 4 \mathrm{~A}}$ overexpression, hereafter denoted as p16, which is associated with superior clinical outcome [21,22]. Thus HPV-positive tumors are characterized by high expression of p16 [23-25] and p16 is widely considered a surrogate marker for HPV infection in the context of squamous cell carcinoma [21, 25].

Some retrospective clinical studies have consistently proved that patients with HPV-positive head and neck squamous cell carcinoma had a better prognosis than patients with HPV-negative tumors [21, 26-28]. Esophagus can be infected with these viruses in the same way as the oral cavity, tonsils, and pharynx; it is supposed that the histological similarities between the head and neck squamous epithelia and esophagus would suggest a similar association and clinical characteristics. The prognostic value of the HPV status has previously been investigated in patients with ESCC. However, the results are much controversial [29-31].

With the present study, we aim to determine the prevalence of HPV infection in ESCC and evaluate its clinical significance. We also sought to evaluate the effect of tumor HPV status on survival of patients with ESCC in northern China.

\section{Patients and Methods}

2.1. Patients and Tissues Samples. A total of 279 patients with primary esophageal carcinoma treated with surgery, admitted to the Oncology Center, Qilu Hospital of Shandong University, were identified from December 2006 to January 2008. This hospital is located in Shandong province, which was a high-incidence area for ESCC in China [32]. Patients treated with neoadjuvant therapy, which could potentially interfere with the prevalence of HPV, were excluded, as were patients who died within 30 days after surgery. The additional exclusion criteria comprised the nonsquamous cell subtype and uncooperative patients unable to answer questions or who could not be contacted. A total of 184 patients met the protocol study criteria. All patients provided their written informed consent regarding this study, and the protocol was approved by the Ethics Committee of Qilu Hospital of Shandong University (documentation no. 2012178). Attempts were made to retrieve paraffin blocks from pathology laboratories at which the patients were diagnosed. Of these, pathology review established that samples from 105 patients had sufficient ESCC tumor tissue to detect HPV and p16. Serial $4 \mu \mathrm{m}$ sections were cut from each patient's tumor tissue. One representative section was stained with hematoxylin and eosin ( $\mathrm{H} \& \mathrm{E})$ to ensure the tissue derived from esophageal cancer. The other sections were prepared for detection. All slides were reviewed by a pathologist specializing in gastrointestinal pathology.

2.2. Followup. Postoperative follow-up data were obtained from all patients. The following parameters were studied: gender, age, tumor location, postoperative pathological $\mathrm{T}$ and
$\mathrm{N}$ status ( $\mathrm{pT}$ and $\mathrm{pN}$ ), TNM staging according to American Joint Committee on Cancer TNM staging system, differentiation grade of the tumor, adjuvant therapy (postoperative radiotherapy with or without chemotherapy), and smoking and alcohol habits. Anatomical localization of the tumor was grouped into an upper part $(15-24 \mathrm{~cm})$, a middle part $(25-$ $34 \mathrm{~cm})$, and a lower part of the esophagus $(35-46 \mathrm{~cm})$. The tumor status was characterized into localized (primary tumor with or without local node metastases) or advanced disease (with distant metastases). Alcohol intake cutoff point was $0.025 \mathrm{~kg} /$ day. The cutoff value was based on the 2011 Chinese Inhabitant Dietary Guideline.

All patients had a regular follow-up schedule including a complete history and physical examination every 3 months during the first 2 years after surgery and every 6 months thereafter. Routine radiological examinations and esophagoscopy were performed when necessary. Patients were followed until death or for a maximum of 5 years.

2.3. $H P V$ Detection. All specimens were evaluated for HPV-16 and HPV-18 with using the in situ hybridizationcatalyzed signal amplification method for biotinylated probes (GenPoint, Dako). Briefly, sections underwent conventional deparaffinization, heat-induced target retrieval was performed, and digestion using proteinase $\mathrm{K}$ and then HPV16 biotinylated DNA probe (GenPoint, Dako) was applied. Sections were then denatured and stained with diaminobenzidine detection system. Sections were counterstained with hematoxylin. All tumors were further evaluated for HPV18 by means of HPV-18 biotinylated DNA probe (GenPoint, Dako). The positive control was a cervical squamous cell carcinoma sample, whereas the negative control was obtained by omitting the HPV probe. All slides were scored as positive or negative. Brown staining confined to nuclei of infected tumor cells was defined positive. All scorings were conducted with no knowledge of p16 immunohistochemistry status.

\section{4. $P 16^{I N K 4 A}$ Immunohistochemistry. P16 immunohisto-} chemical detection was done as described previously [33]. Briefly, after formalin-fixed, paraffin-embedded tumor specimens were deparaffinized, antigen retrieval was performed by use of heat-induced epitope retrieval with Tris-EDTA ( $\mathrm{PH}=9.0$, Dako $)$ according to the manufacturer's recommendations. Processions were carried out by the Dako Envision-System method (code: GK500705) using a primary antibody against p16 (monoclonal mouse anti-human p16 ${ }^{\text {INK4A }}$ protein, Clone G175-405, Dako). A p16-positive tumor was used as a positive control; negative controls were obtained by omitting the primary antibody. P16-positive was defined as $>50 \%$ of cells showing strong nuclear and cytoplasm immunolabeling. All scorings were conducted with no knowledge of clinical characteristics or outcome.

2.5. Statistical Analysis. All analyses were performed using SPSS 16 (SPSS Inc., Chicago, IL). Statistical analyses included univariate analyses of demographic and postoperative outcome data. For these analyses, the differences between the groups were tested for significance using the Mann-Whitney 
test for continuous variables and the chi-square test or Fisher's exact test for categorical variables and the Kruskal-Wallis test for ranked data. The Kaplan-Meier method and log-rank test were used for analysis and comparison of survival curves. The primary end point was overall survival (OS), defined as the time from date of surgery to death. Secondary end points included progression-free survival (PFS), defined as the time from date of surgery to death or the first documented relapse, which was categorized as local-regional disease (tumor at the primary site or regional nodes) or distant metastases. Death from the primary cancer without a documented site of recurrence or death from an unknown cause was considered death from local-regional disease. PFS and its components were adopted to facilitate comparison with published metaanalyses [34]. The Cox proportional hazards model was used to determine the hazard ratio (HR) of variables on 5-year OS and PFS in univariate and multivariate analysis. The results were given as HRs with their 95\% confidence interval (CI). $P$ values less than 0.05 were considered statistically significant.

\section{Results}

3.1. Patient Characteristics. A total of 105 patients (84 males and 21 females) met the protocol study criteria for analysis. The median age of the patients was 60 (range: 42-78) years at the date of surgery. Patients were divided into two groups according to the tumor HPV status. Baseline characteristics of HPV-positive and HPV-negative patients are shown in Table 1. There were no significant differences between the groups with respect to gender $(P=0.66)$, age $(P=0.22)$, pT status $(P=0.18), \mathrm{pN}$ status $(P=0.27)$, TNM stage (AJCC) $(P=0.14)$, differentiation grade $(P=0.21)$, adjuvant therapy $(P=0.41)$, smoking $(P=0.13)$, and alcohol consumption $(P=0.78)$ and only marginally associated with tumor location $(P=0.07)$.

3.2. Analysis of HPV and p16. Twenty-nine (27.6\%) of the 105 ESCC patients were determined to be HPV-positive by in situ hybridization, and all positive cases were HPV16 (Figure 1(a)); none were positive for HPV-18 DNA. The median age of the HPV-positive group was 60 years (range: 44-75 years) and 62 years (range: $42-78$ years) in the HPVnegative group. Twenty-five (86.2\%) of 29 HPV-positive tumors were stained positive for $\mathrm{p} 16$ with immunohistochemistry (Figure 1(b)). P16 expression was strongly associated with HPV positivity (86.2\% in HPV-positive tumors versus $18.4 \%$ in HPV-negative tumors, $P<0.001$ ) (Table 2).

3.3. Survival Analysis. Based on Kaplan-Meier analysis, patients with HPV-positive tumors had better survival than patients with HPV-negative ones ( $P=0.002$, log-rank test). The 5-year rates of OS were $65.9 \%$ in the HPV-positive subgroup and $43.4 \%$ in the HPV-negative one (Figure 2(a)). HPV-positive patients also had statistically significantly better PFS than HPV-negative patients $(P=0.001$, logrank test). The 5-year rates of PFS were $61.8 \%$ and $36.8 \%$, respectively (Figure $2(\mathrm{~b})$ ). Tumors were evaluated for the expression of not only HPV but also a known biomarker
TABLE 1: Baseline characteristics of the study patients and their tumors, according to tumor HPV status.

\begin{tabular}{|c|c|c|c|c|}
\hline Characteristics & $\begin{array}{c}\text { Total } \\
(N=105) \\
\text { no. }(\%)\end{array}$ & $\begin{array}{c}\text { HPV- } \\
\text { positive } \\
(N=29) \\
\text { no. }(\%)\end{array}$ & $\begin{array}{c}\text { HPV- } \\
\text { negative } \\
(N=76) \\
\text { no. }(\%)\end{array}$ & $P$ value \\
\hline \multicolumn{5}{|l|}{ Gender } \\
\hline Male & $84(80.0)$ & $24(82.8)$ & $60(78.9)$ & \multirow{2}{*}{0.66} \\
\hline Female & $21(20.0)$ & $5(17.2)$ & $16(21.1)$ & \\
\hline \multicolumn{5}{|l|}{ Age } \\
\hline Median (range) & $60(42-78)$ & $60(44-75)$ & $62(42-78)$ & $0.22^{\triangle}$ \\
\hline \multicolumn{5}{|l|}{ Tumor location } \\
\hline Cervical/upper & $11(10.5)$ & $6(20.7)$ & $5(6.6)$ & \multirow{3}{*}{0.07} \\
\hline Middle & $49(46.7)$ & $14(48.3)$ & $35(46.1)$ & \\
\hline Low & $45(42.9)$ & $9(31.0)$ & $36(47.4)$ & \\
\hline \multicolumn{5}{|l|}{ pT status } \\
\hline pT1 & $20(19.0)$ & $7(24.1)$ & $13(17.1)$ & \multirow{4}{*}{$0.18^{\text {幽 }}$} \\
\hline pT2 & $22(21.0)$ & $7(24.1)$ & $15(19.7)$ & \\
\hline pT3 & $58(55.2)$ & $15(51.8)$ & $43(56.6)$ & \\
\hline pT4 & $5(4.8)$ & $0(0.0)$ & $5(6.6)$ & \\
\hline \multicolumn{5}{|l|}{ pN status } \\
\hline $\mathrm{pN} 0$ & $68(64.8)$ & $21(72.4)$ & $47(61.8)$ & \multirow{4}{*}{$0.27^{\text {広 }}$} \\
\hline $\mathrm{pN} 1$ & $25(23.8)$ & $6(20.7)$ & $19(25.0)$ & \\
\hline $\mathrm{pN} 2$ & $10(9.5)$ & $2(6.9)$ & $8(10.5)$ & \\
\hline $\mathrm{pN} 3$ & $2(1.9)$ & $0(0.0)$ & $2(2.6)$ & \\
\hline \multicolumn{5}{|l|}{ TNM stage (AJCC) } \\
\hline I & $23(21.9)$ & $7(24.1)$ & $16(21.1)$ & \multirow{3}{*}{0.14} \\
\hline II & $49(46.7)$ & $17(58.6)$ & $32(42.1)$ & \\
\hline III & $33(31.4)$ & $5(17.2)$ & $28(36.8)$ & \\
\hline \multicolumn{5}{|l|}{$\begin{array}{l}\text { Differentiation } \\
\text { grade }\end{array}$} \\
\hline Well & $27(25.7)$ & $11(37.9)$ & $16(21.1)$ & \multirow{3}{*}{0.21} \\
\hline Moderate & $44(41.9)$ & $10(34.5)$ & $34(44.7)$ & \\
\hline Poor & $34(32.4)$ & $8(27.6)$ & $26(34.2)$ & \\
\hline \multicolumn{5}{|l|}{ Adjuvant therapy } \\
\hline No & $61(58.1)$ & $15(51.7)$ & $46(60.5)$ & \multirow{2}{*}{0.41} \\
\hline yes & $44(41.9)$ & $14(48.3)$ & $30(39.5)$ & \\
\hline \multicolumn{5}{|l|}{$\begin{array}{l}\text { Pack-years of } \\
\text { smoking }^{*}\end{array}$} \\
\hline$<20$ & $42(40.0)$ & 15 (51.7) & $27(35.5)$ & \multirow{2}{*}{0.13} \\
\hline$\geq 20$ & $63(60.0)$ & $14(48.3)$ & $49(64.5)$ & \\
\hline \multicolumn{5}{|l|}{$\begin{array}{l}\text { Alcohol intake } \\
\text { (kg/day) }\end{array}$} \\
\hline$<20$ & $53(50.5)$ & $14(48.3)$ & $39(51.3)$ & \multirow{2}{*}{0.78} \\
\hline$\geq 20$ & $52(49.5)$ & $15(51.7)$ & $37(48.7)$ & \\
\hline
\end{tabular}

AJCC: American Joint Commission on Cancer Staging; Pt: pathological tumor stage; $\mathrm{pN}$ : pathological node stage.

${ }^{2} P$ values were calculated with the use of the Kruskal-Wallis test.

${ }^{\triangle} P$ values were calculated with the use of the Mann-Whitney test.

${ }^{*}$ A pack-year is defined as the equivalent of smoking one pack of cigarettes per day for 1 year.

of HPV oncoprotein function, the cyclin-dependent-kinase inhibitor p16, which is minimally detectable in HPV-negative 


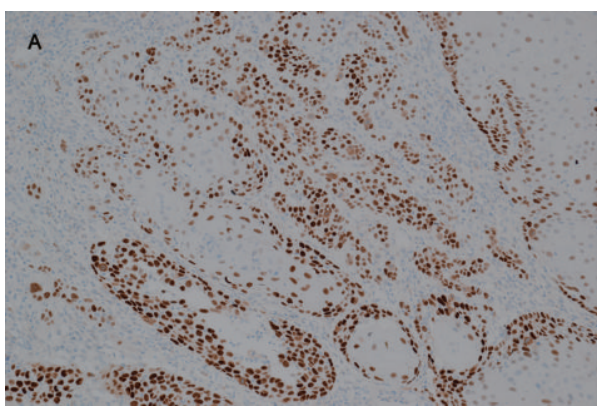

(a)

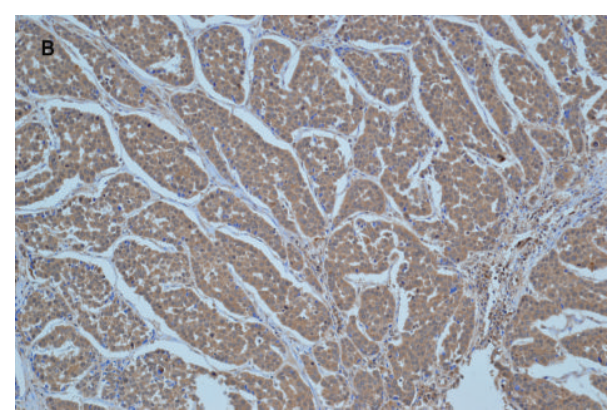

(b)

FIGURE 1: (a) In situ hybridization signal of HPV-positive esophageal squamous cell carcinomas. Numerous tumor cells show positive nuclear signals. (b) Immunohistochemical staining of $16^{1 \mathrm{INK} 4 \mathrm{~A}}$ in esophageal squamous cell carcinomas. More than $50 \%$ of tumor cells showing strong nuclear and cytoplasm immunolabeling. (Original magnification $\times 200$.)

TABLE 2: Correlation between HPV in situ hybridization and p16 immunohistochemistry in esophageal squamous cell carcinoma.

\begin{tabular}{|c|c|c|c|c|c|}
\hline p16 status & $\begin{array}{c}\text { Total } \\
(N=105) \\
\text { no. }(\%)\end{array}$ & $\begin{array}{c}\text { HPV- } \\
\text { positive } \\
(N=29) \\
\text { no. }(\%)\end{array}$ & $\begin{array}{c}\text { HPV- } \\
\text { negative } \\
(N=76) \\
\text { no. }(\%)\end{array}$ & $P$ value & $\begin{array}{l}\text { Kappa } \\
\text { value }\end{array}$ \\
\hline Positive & 39 (37.1) & $25(86.2)$ & $14(18.4)$ & \multirow{2}{*}{$<0.001$} & \multirow{2}{*}{0.61} \\
\hline Negative & 66 (62.9) & $4(13.8)$ & $62(81.6)$ & & \\
\hline
\end{tabular}

$P$ and Kappa values were calculated with the use of Pearson's chi-square test and Cohen Kappa test, respectively.

tumors [35]. The presence of HPV and p16 expression in tumors had a good agreement (kappa $=0.61 ; 95 \%$ CI: 0.45 to 0.77$)$. Using p16 expression as a stratification factor, we found differences in OS and PFS that were consistent with those based on HPV status. The 5-year rates of OS were $64.1 \%$ in the subgroup that was positive for p16 expression and $45.5 \%$ in the negative subgroup $(P=0.021$, log-rank test $)$ (Figure 2(c)). The 5-year rates of PFS were $58.7 \%$ and $37.9 \%$, respectively $(P=0.007$, log-rank test) (Figure $2(\mathrm{~d})$ ).

Univariate analysis was performed to evaluate factors potentially associated with OS and PFS (Table 3). Gender, age, tumor location, differentiation grade of the tumor, adjuvant therapy, and alcohol habits were not important determinants of survival or PFS. However, $\mathrm{pT}$ and $\mathrm{pN}$ status, TNM staging, and smoking and tumor HPV status were associated with OS or PFS. T status (T1/T2 versus T3/T4, $\mathrm{HR}=3.44$, and $95 \% \mathrm{CI}=1.85$ to 6.40 ), $\mathrm{N}$ status (N0 versus $\mathrm{N} 1 / \mathrm{N} 2 / \mathrm{N} 3, \mathrm{HR}$ $=2.71$, and $95 \% \mathrm{CI}=1.55$ to 4.73 ), $\mathrm{TNM}$ stage (AJCC stage I/II versus III/IV, $\mathrm{HR}=3.04$, and $95 \% \mathrm{CI}=1.74$ to 5.32 ), and tumor HPV status (positive versus negative, $\mathrm{HR}=3.26$, and $95 \% \mathrm{CI}=1.46$ to 7.25 ) were associated with OS. $\mathrm{T}$ status (T1/T2 versus $\mathrm{T} 3 / \mathrm{T} 4, \mathrm{HR}=2.42$, and $95 \% \mathrm{CI}=1.40$ to 4.19 ), $\mathrm{N}$ status (N0 versus $\mathrm{N} 1 / \mathrm{N} 2 / \mathrm{N} 3, \mathrm{HR}=2.79$, and $95 \% \mathrm{CI}=$ 1.66 to 4.72 ), TNM stage (AJCC stage I/II versus III/IV, HR $=2.66$, and $95 \% \mathrm{CI}=1.57$ to 4.50 ), and tumor HPV status (positive versus negative, $\mathrm{HR}=3.01$, and $95 \% \mathrm{CI}=1.50$ to 6.17) were associated with PFS. The association of tumor HPV status with survival could not be explained by smoking: patients with HPV-positive tumors with or without a history of smoking had a similar reduction in risk of mortality when compared with their HPV-negative counterparts. Tobacco smoking was also associated with OS and PFS both in the subgroup of patients ( $<20$ versus $\geq 20, \mathrm{HR}=1.88$, and $95 \% \mathrm{CI}$ $=1.03$ to 3.45 and $\mathrm{HR}=1.96$ and $95 \% \mathrm{CI}=1.11$ to 3.45 , resp.).

We then performed multivariable analysis to estimate the association of tumor HPV status with survival outcomes (Table 4). In this analysis, $\mathrm{T}$ status (T1/T2 versus $\mathrm{T} 3 / \mathrm{T} 4$, adjusted $\mathrm{HR}=2.65,95 \% \mathrm{CI}=1.39$ to 5.05 , and $P=0.003$ ), $\mathrm{N}$ status (N0 versus $\mathrm{N} 1 / \mathrm{N} 2 / \mathrm{N} 3$, adjusted $\mathrm{HR}=2.07,95 \% \mathrm{CI}=$ 1.16 to 3.72 , and $P=0.01$ ), and TNM stage (I/II versus III/IV, adjusted $\mathrm{HR}=1.91,95 \% \mathrm{CI}=0.28$ to 2.43 , and $P=0.04$ ) were associated with degraded mortality risk after adjustment for smoking and tumor HPV status. Tumor HPV status was independently associated with mortality risk after adjustment for $\mathrm{pT}$ status, $\mathrm{pN}$ status, TNM stage, and smoking: patients with HPV-positive tumors had a $63 \%$ lower risk of death than patients with HPV-negative (adjusted $\mathrm{HR}=0.37,95 \% \mathrm{CI}=$ 0.16 to 0.82 , and $P=0.01$ ). After adjustment for $\mathrm{pT}$ status, $\mathrm{pN}$ status, TNM stage, and smoking, tumor HPV status was also statistically significantly associated with PFS. Patients with HPV-positive tumors had a risk of progression that was $62 \%$ lower than that of patients with HPV-negative tumors (adjusted $\mathrm{HR}=0.38,95 \% \mathrm{CI}=0.18$ to 0.77 , and $P=0.008$ ).

\section{Discussion}

HPV is a small double-stranded DNA virus with tropism for the squamous epithelium where it can cause hyperproliferative lesions [19]. There are more than 130 HPV types identified and these have been classified into low- or highrisk groups according to their potential for oncogenesis [36]. The high-risk HPV types are closely related to malignancies. According to previous studies, HPV-16 is the most prevalent type in squamous cell carcinoma, followed by HPV-18 [37], while other high-risk HPV types are rare [38, 39].

The etiological role of HPV in ESCC is still unclear. The incidence of HPV in ESCC varies between different geographical areas [9]. It is postulated that areas with high incidence of esophageal carcinoma have higher rates of HPV than areas with low incidence of esophageal carcinoma [40]. In our study, we observed an association between HPV 
TABLE 3: Cox univariate analysis for 5-year survival and progression-free survival in the study patients with esophageal squamous cell carcinoma.

\begin{tabular}{|c|c|c|c|c|c|c|}
\hline \multirow{3}{*}{ Parameters } & \multicolumn{6}{|c|}{ Univariate analysis } \\
\hline & \multicolumn{3}{|c|}{ 5-yr overall survival } & \multicolumn{3}{|c|}{ 5-yr progression-free survival } \\
\hline & HR & $95 \% \mathrm{CI}$ & $P$ value & HR & $95 \% \mathrm{CI}$ & $P$ value \\
\hline $\begin{array}{l}\text { Gender } \\
\text { Male versus female }\end{array}$ & 1.29 & $0.68-2.47$ & 0.44 & 1.32 & $0.71-2.45$ & 0.38 \\
\hline $\begin{array}{l}\text { Age } \\
\qquad<60 \text { versus } \geq 60\end{array}$ & 0.98 & $0.56-1.70$ & 0.93 & 0.85 & $0.51-1.44$ & 0.55 \\
\hline $\begin{array}{l}\text { Location } \\
\text { Cervical/upper versus middle/low }\end{array}$ & 0.75 & $0.30-1.89$ & 0.54 & 0.66 & $0.28-1.55$ & 0.34 \\
\hline $\begin{array}{l}\text { Differentiation } \\
\text { Well/moderate versus poor }\end{array}$ & 1.01 & $0.56-1.81$ & 0.99 & 1.12 & $0.58-2.14$ & 0.74 \\
\hline $\begin{array}{l}\text { pT status } \\
\text { T1/T2 versus T3/T4 }\end{array}$ & 3.44 & $1.85-6.40$ & $<0.001$ & 2.42 & $1.40-4.19$ & 0.002 \\
\hline $\begin{array}{l}\mathrm{pN} \text { status } \\
\mathrm{N} 0 \text { versus } \mathrm{N} 1 / \mathrm{N} 2 / \mathrm{N} 3\end{array}$ & 2.71 & $1.55-4.73$ & $<0.001$ & 2.79 & $1.66-4.72$ & 0.001 \\
\hline $\begin{array}{l}\text { TNM stage } \\
\text { I/II versus III/IV }\end{array}$ & 3.04 & $1.74-5.32$ & $<0.001$ & 2.66 & $1.57-4.50$ & $<0.001$ \\
\hline $\begin{array}{l}\text { Adjuvant therapy } \\
\text { No versus yes }\end{array}$ & 0.75 & $0.54-1.53$ & 0.35 & 0.51 & $0.45-1.28$ & 0.12 \\
\hline $\begin{array}{l}\text { Pack-years of smoking } \\
\quad<20 \text { versus } \geq 20\end{array}$ & 1.88 & $1.03-3.45$ & 0.04 & 1.96 & $1.11-3.45$ & 0.02 \\
\hline $\begin{array}{r}\text { Alcohol intake }(\mathrm{kg} / \text { day }) \\
<0.025 \text { versus } \geq 0.025\end{array}$ & 1.66 & $0.95-2.92$ & 0.08 & 1.61 & $0.95-2.73$ & 0.06 \\
\hline $\begin{array}{l}\text { Tumor HPV status } \\
\text { Negative versus positive }\end{array}$ & 0.31 & $0.14-0.68$ & 0.004 & 0.33 & $0.16-0.67$ & 0.002 \\
\hline $\begin{array}{l}\text { Tumor HPV status } \\
\text { Positive versus negative }\end{array}$ & 3.26 & $1.46-7.25$ & 0.004 & 3.01 & $1.50-6.17$ & 0.002 \\
\hline
\end{tabular}

HR: hazard ratio; CI: confidence interval; a pack-year: the equivalent of smoking one pack of cigarettes per day for 1 year.

infection and ESCC, HPV was detected in $27.6 \%$ of the cases by the use of in situ hybridization, and all cases were HPV16 positive. The observation was consistent with the previous studies in high-risk areas for ESCC in China [29, 39, 41, 42].

In the present study, we also found that there were marginally significant differences between the HPV-positive and -negative $\operatorname{ESCC}(P=0.07)$ with tumor location. $\mathrm{HPV}$ infection in upper esophagus was higher than lower. Potentially possible causes were the route of HPV infection and the histological similarities between the oropharyngeal squamous epithelia and upper digestive tract. HPV is currently one of the most common sexually transmitted infections worldwide [43]. Numerous studies have examined that changes in sexual behavior may be able to explain the increase in the incidence of HPV-positive cancers $[44,45]$. Esophagus can be infected with these viruses in the same way as the oral cavity, tonsils, and pharynx.

In our study, $25(86.2 \%)$ of the $29 \mathrm{HPV}$-positive ESCC cases expressed p16, while 14 (18.4\%) of 76 HPV-negative subgroup. We observed strong agreement between tumor HPV status by in situ hybridization and p16 by immunohistochemistry, an established biomarker for the function of the HPV E7 oncoprotein. HPV in situ hybridization assay has sensitivity for single viral copies, and a positive result is strongly correlated with expression of the HPV E6 and E7 oncogenes which is the standard for defining a tumor as being effected with HPV [46, 47]. A restriction of our study is not to detect the other subtypes except HPV-16/18, the misclassification of HPV-positive tumors, as HPV-negative tumors probably emerge. The expression of p16 is not specific for HPV type; therefore, p16 immunohistochemistry is a very good surrogate marker of HPV infection for ESCC.

The prognostic value of HPV status has previously been investigated in patients with ESCC. However, the results were much controversial. Furihata et al. reported that HPVpositive patients had worse survival than HPV-negative patients with an overexpression of p53 in esophageal carcinoma patients; they concluded that HPV infection and p53 overexpression indicate poor prognosis [30]. Hippeläinen et al. reported that HPV were involved in $11 \%$ of 61 patients with ESCC but without prognostic value [29]. Dreilich et al. reported patients with a HPV-16 viral load > 1.0 viral genome per cell had higher survival rates compared to patients with a HPV-16 viral load $<1.0$ viral genome per cell [31].

On the basis of our data, tumor HPV status was an independent prognostic factor for OS and PFS among patients 
TABLE 4: Multivariate Cox analysis for 5-year survival and progression-free survival in the study patients with esophageal squamous cell carcinoma.

\begin{tabular}{|c|c|c|c|c|c|c|}
\hline \multirow{3}{*}{ Parameters } & \multicolumn{6}{|c|}{ Multivariate analysis } \\
\hline & \multicolumn{3}{|c|}{ 5-yr overall survival } & \multicolumn{3}{|c|}{ 5-yr progression-free survival } \\
\hline & $\mathrm{HR}$ & $95 \% \mathrm{CI}$ & $P$ value & HR & $95 \% \mathrm{CI}$ & $P$ value \\
\hline $\begin{array}{l}\text { pT status } \\
\text { T1/T2 versus T3/T4 }\end{array}$ & 2.65 & $1.39-5.05$ & 0.003 & 2.09 & $1.17-3.72$ & 0.01 \\
\hline $\begin{array}{l}\mathrm{pN} \text { status } \\
\mathrm{N} 0 \text { versus } \mathrm{N} 1 / \mathrm{N} 2 / \mathrm{N} 3\end{array}$ & 2.07 & $1.16-3.72$ & 0.01 & 2.14 & $1.24-3.68$ & 0.006 \\
\hline $\begin{array}{l}\text { TNM stage } \\
\text { I/II versus III/IV }\end{array}$ & 1.91 & $0.28-2.43$ & 0.04 & 0.48 & $0.15-2.47$ & 0.03 \\
\hline $\begin{array}{l}\text { Pack-years of smoking } \\
\quad<20 \text { versus } \geq 20\end{array}$ & 1.84 & $1.00-3.39$ & 0.06 & 1.94 & $1.09-3.44$ & 0.02 \\
\hline $\begin{array}{l}\text { Tumor HPV status } \\
\text { Positive versus negative }\end{array}$ & 0.37 & $0.16-0.82$ & 0.01 & 0.38 & $0.18-0.77$ & 0.008 \\
\hline
\end{tabular}

HR: hazard ratio; CI: confidence interval; a pack-year: the equivalent of smoking one pack of cigarettes per day for 1 year.

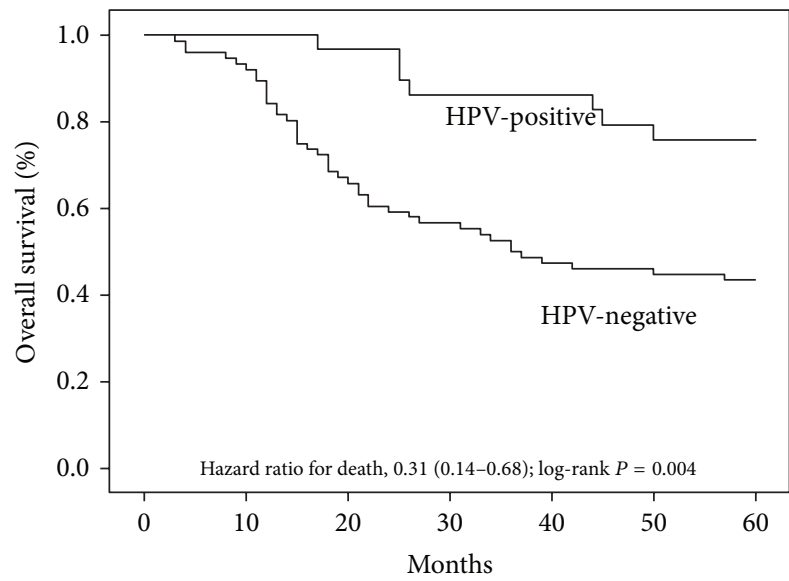

(a) Overall survival according to tumor HPV status

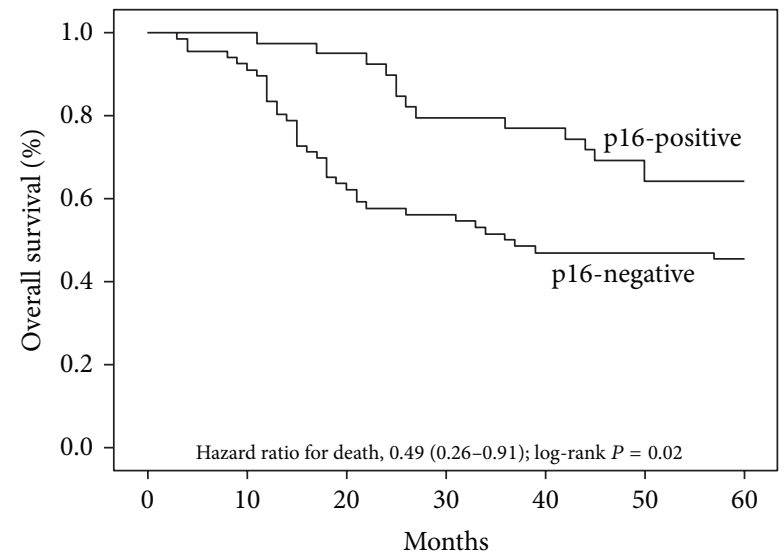

(c) Overall survival according to p16 expression

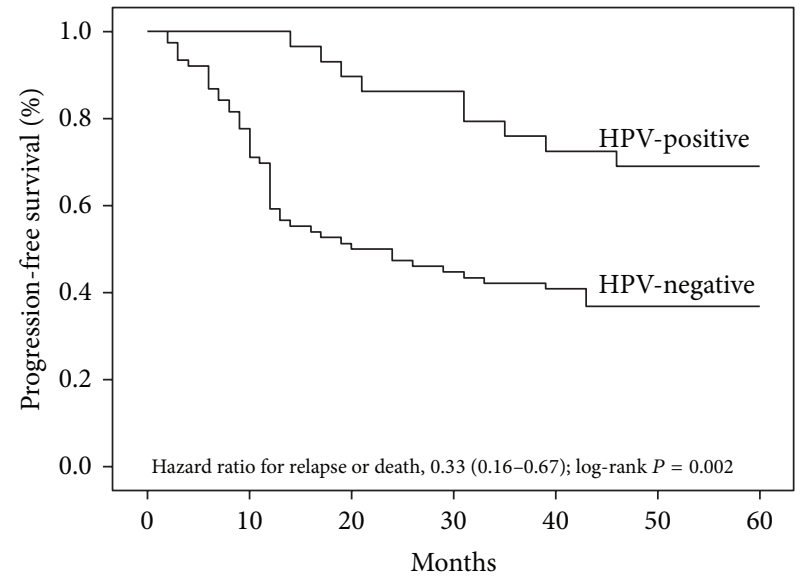

(b) Progression-free survival according to tumor HPV status

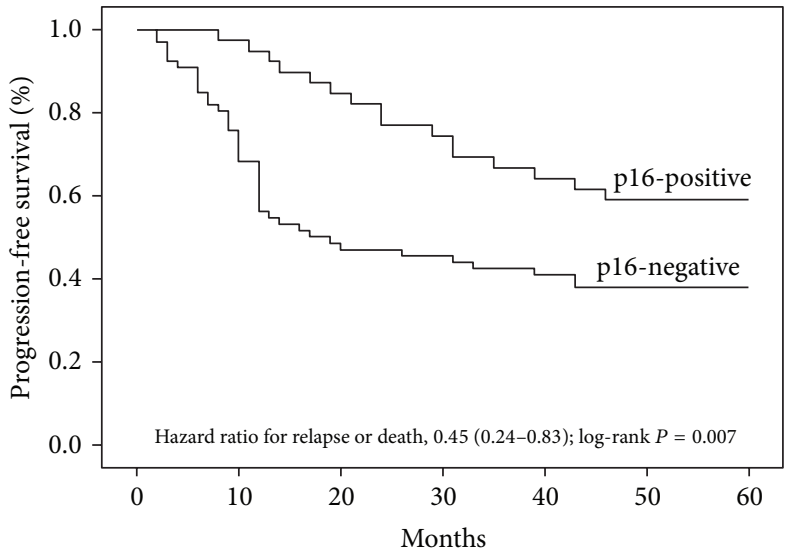

(d) Progression-free survival according to p16 expression

FIGURE 2: Kaplan-Meier estimates of survival among the study patients, according to tumor HPV status or p16-expression status. For 5-year overall survival rate (a) and 5-year progression-free survival rate (b), HPV was significantly associated with improved outcomes $(P=0.002$, $P=0.001$, resp.). For 5-year OS rate (c) and 5-year progression-free survival rate (d), p16 was significantly associated with improved outcomes $(P=0.021, P=0.007$, resp.). 
with ESCC. Other retrospective researches have also consistently demonstrated that patients with HPV-positive tumors have a superior prognosis than patients with HPV-negative ones [23, 28, 48, 49]. Several hypotheses have been proposed to explain these results. Cisplatin sensitivity is increased in HPV-16 transfected ovarian cancer cells in vitro studies [50], which imply a better prognosis. HPV-DNA integration is confined to the neoplastic and dysplastic tissue only, so no effect is observed in the field cancerization in HPV-positive tumors $[51,52]$. The relationship between the immune system, HPV status, and outcome remains an interesting area of ongoing research; a higher percentage of CD8 cells in the peripheral blood and a lower CD4/CD8 ratio and higher mean sum of CD4 and CD8 infiltrates in the tumor microenvironment may be predictive of better outcome [53]. Integration of HPV results in higher expression of the oncoproteins E6/E7, thereby abrogating the p53 and Rb protein functions, promoting genomic rearrangements [54]; rearranged DNA is theoretically more sensitive to radiation and chemotherapy, providing an explanation for the indication of higher survival rates for patients with HPV-positive tumors. Therefore, the biologic basis for the improved survival among the HPVpositive patients is unclear and warrants further study.

Smoking is associated with an increased risk of ESCC [55] and a poor outcome [22]. In the present study, patients with pack-years of smoking $<20$ indicated a trend towards better survival than patients with pack-years of smoking $\geq$ 20 , although this was not statistically significant $(P=0.06)$. However, patients with pack-years of smoking $<20$ had a $49 \%$ reduction in their risk of progression compared with patients with pack-years of smoking $\geq 20(P=0.02)$. The link between HPV positivity in ESCC and smoking was still under investigation. Some studies have suggested synergistic effect $[16,56]$ while others have not $[18,57]$. Genetic alterations induced by tobacco-associated carcinogens may be strengthened by HPV and cause HPV-positive tumors less sensitive to treatment. Our sample was too small to exclude confounding by smoking, although there was no apparent difference in the prevalence of smoking intake among patients with HPV-positive versus HPV-negative. Analysis of a larger study could more thoroughly evaluate the possibility of confounding by smoking via analysis of different levels of tobacco consumption.

Additional variables of potential prognostic importance, such as weight loss, anemia, performance status, dietary habits, and sexual behavior, were lacking in our study. Sample size limits the number of variables that could be included in our models. Factors not included in our models may be important and affect survival. Although statistically significant differences in survival were observed between HPV-positive and -negative, definitive conclusions cannot be drawn from this study due to its small sample size and retrospective nature; larger confirmatory studies are needed to provide definitive evidence.

In addition, the temporal sequence of HPV infection and onset of ESCC cannot be ascertained. Therefore, a causal relationship between exposure and outcome must be a tentative one, despite the association of infection and tumor which has been observed. A prospective study would be needed to further address this issue. The role of viruses has great potential in the clinical practice, particularly when investigated in combination with other factors. This study provides a direction for future clinical research. However, given the limited sample size, the results of this study should be interpreted with caution.

\section{Conflict of Interests}

The authors declared that there is no conflict of interests regarding the publication of this paper.

\section{Acknowledgments}

This work was supported by China Postdoctoral Science Fund (no. 2011M500531) and Science and Technology development Planning of Shandong province (no. 2012GGE27088). The authors thank Dr. Junlong Xu (pathologist from the Department of Pathology, Liaocheng People's Hospital, Liaocheng, China) for his expert suggestions and technical assistance.

\section{References}

[1] J. Ferlay, H.-R. Shin, F. Bray, D. Forman, C. Mathers, and D. M. Parkin, "Estimates of worldwide burden of cancer in 2008: GLOBOCAN 2008," International Journal of Cancer, vol. 127, no. 12, pp. 2893-2917, 2010.

[2] A. Jemal, F. Bray, M. M. Center, J. Ferlay, E. Ward, and D. Forman, "Global cancer statistics," CA Cancer Journal for Clinicians, vol. 61, no. 2, pp. 69-90, 2011.

[3] J.-M. Collard, J.-B. Otte, R. Fiasse et al., "Skeletonizing en bloc esophagectomy for cancer," Annals of Surgery, vol. 234, no. 1, pp. 25-32, 2001.

[4] J. M. Risk, H. S. Mills, J. Garde et al., "The tylosis esophageal cancer (TOC) locus: more than just a familial cancer gene," Diseases of the Esophagus, vol. 12, no. 3, pp. 173-176, 1999.

[5] W.-Q. Wei, J. Yang, S.-W. Zhang, W.-Q. Chen, and Y.-L. Qiao, "Analysis of the esophageal cancer mortality in 2004-2005 and its trends during last 30 years in China," Chinese journal of preventive medicine, vol. 44, no. 5, pp. 398-402, 2010.

[6] C. Gholipour, R. A. Shalchi, and M. Abbasi, "A histopathological study of esophageal cancer on the western side of the Caspian littoral from 1994 to 2003," Diseases of the Esophagus, vol. 21, no. 4, pp. 322-327, 2008.

[7] R. S. Holmes and T. L. Vaughan, "Epidemiology and pathogenesis of esophageal cancer," Seminars in Radiation Oncology, vol. 17, no. 1, pp. 2-9, 2007.

[8] W.-Q. Wei, C. C. Abnet, Y.-L. Qiao et al., "Prospective study of serum selenium concentrations and esophageal and gastric cardia cancer, heart disease, stroke, and total death," The American Journal of Clinical Nutrition, vol. 79, no. 1, pp. 80-85, 2004.

[9] K. J. Syrjänen, "HPV infections and oesophageal cancer," Journal of Clinical Pathology, vol. 55, no. 10, pp. 721-728, 2002.

[10] K. J. Syrjänen, "Histological changes identical to those of condylomatous lesions found in esophageal squamous cell carcinomas," Archiv fur Geschwulstforschung, vol. 52, no. 4, pp. 283-292, 1982.

[11] F. Chang, S. Syrjänen, Q. Shen et al., "Evaluation of HPV, CMV, $\mathrm{HSV}$ and EBV in esophageal squamous cell carcinomas from 
a high-incidence area of China," Anticancer Research, vol. 20, no. 5 C, pp. 3935-3940, 2000.

[12] N. Muñoz, F. X. Bosch, S. de Sanjosé et al., "Epidemiologic classification of human papillomavirus types associated with cervical cancer," The New England Journal of Medicine, vol. 348, no. 6, pp. 518-527, 2003.

[13] J. M. Walboomers, M. V. Jacobs, M. M. Manos et al., "Human papillomavirus is a necessary cause of invasive cervical cancer worldwide," The Journal of Pathology, vol. 189, no. 1, pp. 12-19, 1999.

[14] P. Naucler, H.-C. Chen, K. Persson et al., "Seroprevalence of human papillomaviruses and Chlamydia trachomatis and cervical cancer risk: nested case-control study," Journal of General Virology, vol. 88, no. 3, pp. 814-822, 2007.

[15] W. Meschede, K. Zumbach, J. Braspenning et al., "Antibodies against early proteins of human papillomaviruses as diagnostic markers for invasive cervical cancer," Journal of Clinical Microbiology, vol. 36, no. 2, pp. 475-480, 1998.

[16] R. Herrero, X. Castellsagué, M. Pawlita et al., "Human papillomavirus and oral cancer: the international agency for research on cancer multicenter study," Journal of the National Cancer Institute, vol. 95, no. 23, pp. 1772-1783, 2003.

[17] K. Zumbach, M. Hoffmann, T. Kahn et al., "Antibodies against oncoproteins E6 and E7 of human papillomavirus types 16 and 18 in patients with head -and-neck squamous-cell carcinoma," International Journal of Cancer, vol. 85, no. 6, pp. 815-818, 2000.

[18] G. D’Souza, A. R. Kreimer, R. Viscidi et al., "Case-control study of human papillomavirus and oropharyngeal cancer," The New England Journal of Medicine, vol. 356, no. 19, pp. 1944-1956, 2007.

[19] H. Zur Hausen, "Papillomaviruses and cancer: from basic studies to clinical application," Nature Reviews Cancer, vol. 2, no. 5, pp. 342-350, 2002.

[20] K. Münger and P. M. Howley, "Human papillomavirus immortalization and transformation functions," Virus Research, vol. 89, no. 2, pp. 213-228, 2002.

[21] N. Reimers, H. U. Kasper, S. J. Weissenborn et al., "Combined analysis of HPV-DNA, p16 and EGFR expression to predict prognosis in oropharyngeal cancer," International Journal of Cancer, vol. 120, no. 8, pp. 1731-1738, 2007.

[22] B. Kumar, K. G. Cordell, J. S. Lee et al., "EGFR, p16, HPV titer, $\mathrm{Bcl}-\mathrm{xL}$ and $\mathrm{p} 53$, sex, and smoking as indicators of response to therapy and survival in oropharyngeal cancer," Journal of Clinical Oncology, vol. 26, no. 19, pp. 3128-3137, 2008.

[23] C. Fakhry, W. H. Westra, S. Li et al., "Improved survival of patients with human papillomavirus-positive head and neck squamous cell carcinoma in a prospective clinical trial," Journal of the National Cancer Institute, vol. 100, no. 4, pp. 261-269, 2008.

[24] L. Licitra, F. Perrone, P. Bossi et al., "High-risk human papillomavirus affects prognosis in patients with surgically treated oropharyngeal squamous cell carcinoma," Journal of Clinical Oncology, vol. 24, no. 36, pp. 5630-5636, 2006.

[25] S. J. Smeets, A. T. Hesselink, E.-J. M. Speel et al., "A novel algorithm for reliable detection of human papillomavirus in paraffin embedded head and neck cancer specimen," International Journal of Cancer, vol. 121, no. 11, pp. 2465-2472, 2007.

[26] S. Syrjänen, "HPV infections and tonsillar carcinoma," Journal of Clinical Pathology, vol. 57, no. 5, pp. 449-455, 2004.

[27] C. S. Kong, B. Narasimhan, H. Cao et al., "The relationship between human papillomavirus status and other molecular prognostic markers in head and neck squamous cell carcinomas," International Journal of Radiation Oncology Biology Physics, vol. 74, no. 2, pp. 553-561, 2009.

[28] P. M. Weinberger, Z. Yu, B. G. Haffty et al., "Molecular classification identifies a subset of human papillomavirus- associated oropharyngeal cancers with favorable prognosis," Journal of Clinical Oncology, vol. 24, no. 5, pp. 736-747, 2006.

[29] M. Hippeläinen, M. Eskelinen, P. Lipponen, F. Chang, and K. Syrjänen, "Mitotic activity index, volume corrected mitotic index and human papilloma-virus suggestive morphology are not prognostic factors in carcinoma of the oesophagus," Anticancer Research, vol. 13, no. 3, pp. 677-681, 1993.

[30] M. Furihata, Y. Ohtsuki, S. Ogoshi, A. Takahashi, T. Tamiya, and T. Ogata, "Prognostic significance of human papillomavirus genomes (type-16, -18) and aberrant expression of $\mathrm{p} 53$ protein in human esophageal cancer," International Journal of Cancer, vol. 54, no. 2, pp. 226-230, 1993.

[31] M. Dreilich, M. Bergqvist, M. Moberg et al., "High-risk human papilloma virus (HPV) and survival in patients with esophageal carcinoma: a pilot study," BMC Cancer, vol. 6, article 94, 2006.

[32] S. Zheng, L. Vuitton, I. Sheyhidin, D. A. Vuitton, Y. Zhang, and X. Lu, "Northwestern China: a place to learn more on oesophageal cancer. Part one: behavioural and environmental risk factors," European Journal of Gastroenterology and Hepatology, vol. 22, no. 8, pp. 917-925, 2010.

[33] A. Saqi, T. L. Pasha, C. M. McGrath, G. H. Yu, P. Zhang, and P. Gupta, "Overexpression of pl6INK4A in liquid-based specimens (SurePath) as marker of cervical dysplasia and neoplasia," Diagnostic Cytopathology, vol. 27, no. 6, pp. 365-370, 2002.

[34] S. Michiels, A. Le Maître, M. Buyse et al., "Surrogate endpoints for overall survival in locally advanced head and neck cancer: meta-analyses of individual patient data," The Lancet Oncology, vol. 10, no. 4, pp. 341-350, 2009.

[35] A. L. Reed, J. Califano, P. Cairns et al., "High frequency of p16 (CDKN2/MTS-1/INK4A) inactivation in head and neck squamous cell carcinoma," Cancer Research, vol. 56, no. 16, pp. 3630-3633, 1996.

[36] H. zur Hausen, "Papillomaviruses in the causation of human cancers-a brief historical account," Virology, vol. 384, no. 2, pp. 260-265, 2009.

[37] N. Muñoz, "Human papillomavirus and cancer: the epidemiological evidence," Journal of Clinical Virology, vol. 19, no. 1-2, pp. $1-5,2000$.

[38] M. Moberg, I. Gustavsson, and U. Gyllensten, "Real-time pcrbased system for simultaneous quantification of human papillomavirus types associated with high risk of cervical cancer," Journal of Clinical Microbiology, vol. 41, no. 7, pp. 3221-3228, 2003.

[39] J. Mork, A. K. Lie, E. Glattre et al., "Human papillomavirus infection as a risk factor for squamous-cell carcinoma of the head and neck," The New England Journal of Medicine, vol. 344, no. 15, pp. 1125-1131, 2001.

[40] Z.-Y. Shen, S.-P. Hu, L.-C. Lu et al., "Detection of human papillomavirus in esophageal carcinoma," Journal of Medical Virology, vol. 68, no. 3, pp. 412-416, 2002.

[41] Y. Gao, N. Hu, X. Han et al., "Family history of cancer and risk for esophageal and gastric cancer in Shanxi, China," BMC Cancer, vol. 9, article 269, 2009.

[42] D. Wen, B. Shan, S. Wang et al., "A positive family history of esophageal/gastric cardia cancer with gastric cardia adenocarcinoma is associated with a younger age at onset and more likely 
with another synchronous esophageal/gastric cardia cancer in a Chinese high-risk area," European Journal of Medical Genetics, vol. 53, no. 5, pp. 250-255, 2010.

[43] J. G. Baseman and L. A. Koutsky, "The epidemiology of human papillomavirus infections," Journal of Clinical Virology, vol. 32, pp. S16-S24, 2005.

[44] D. Herbenick, M. Reece, V. Schick, S. A. Sanders, B. Dodge, and J. D. Fortenberry, "Sexual behavior in the United States: results from a national probability sample of men and women ages 1494," Journal of Sexual Medicine, vol. 7, no. 5, pp. 255-265, 2010.

[45] N. Bajos, M. Bozon, N. Beltzer et al., "Changes in sexual behaviours: from secular trends to public health policies," AIDS, vol. 24, no. 8, pp. 1185-1191, 2010.

[46] H. de Vuyst, G. M. Clifford, M. C. Nascimento, M. M. Madeleine, and S. Franceschi, "Prevalence and type distribution of human papillomavirus in carcinoma and intraepithelial neoplasia of the vulva, vagina and anus: a meta-analysis," International Journal of Cancer, vol. 124, no. 7, pp. 1626-1636, 2009.

[47] D. M. Parkin, F. Bray, J. Ferlay, and P. Pisani, "Global cancer statistics, 2002," CA Cancer Journal for Clinicians, vol. 55, no. 2, pp. 74-108, 2005.

[48] M. L. Gillison, W. M. Koch, R. B. Capone et al., "Evidence for a causal association between human papillomavirus and a subset of head and neck cancers," Journal of the National Cancer Institute, vol. 92, no. 9, pp. 709-720, 2000.

[49] K. K. Ang, J. Harris, R. Wheeler et al., "Human papillomavirus and survival of patients with oropharyngeal cancer," The New England Journal of Medicine, vol. 363, no. 1, pp. 24-35, 2010.

[50] K. E. Pestell, S. M. Hobbs, J. C. Titley, L. R. Kelland, and M. I. Walton, "Effect of p53 status on sensitivity to platinum complexes in a human ovarian cancer cell line," Molecular Pharmacology, vol. 57, no. 3, pp. 503-511, 2000.

[51] S. Begum, D. Cao, M. Gillison, M. Zahurak, and W. H. Westra, "Tissue distribution of human papillomavirus 16 DNA integration in patients with tonsillar carcinoma," Clinical Cancer Research, vol. 11, no. 16, pp. 5694-5699, 2005.

[52] S. L. McGovern, M. D. Williams, R. S. Weber et al., “Three synchronous HPV-associated squamous cell carcinomas of Waldeyer's ring: case report and comparison with Slaughter's model of field cancerization," Head and Neck, vol. 32, no. 8, pp. 1118-1124, 2010.

[53] D. Wansom, E. Light, D. Thomas et al., "Infiltrating lymphocytes and human papillomavirus-16-associated oropharyngeal cancer," The Laryngoscope, vol. 122, no. 1, pp. 121-127, 2012.

[54] L. Dahlgren, H. Mellin, D. Wangsa et al., "Comparative genomic hybridization analysis of tonsillar cancer reveals a different pattern of genomic imbalances in human papillomaviruspositive and -negative tumors," International Journal of Cancer, vol. 107, no. 2, pp. 244-249, 2003.

[55] S. S. Hecht, "Cigarette smoking: cancer risks, carcinogens, and mechanisms," Langenbeck's Archives of Surgery, vol. 391, no. 6, pp. 603-613, 2006.

[56] S. M. Schwartz, J. R. Daling, D. R. Doody et al., "Oral cancer risk in relation to sexual history and evidence of human papillomavirus infection," Journal of the National Cancer Institute, vol. 90, no. 21, pp. 1626-1636, 1998.

[57] K. M. Applebaum, C. S. Furniss, A. Zeka et al., "Lack of association of alcohol and tobacco with HPV16-associated head and neck cancer," Journal of the National Cancer Institute, vol. 99, no. 23, pp. 1801-1810, 2007. 


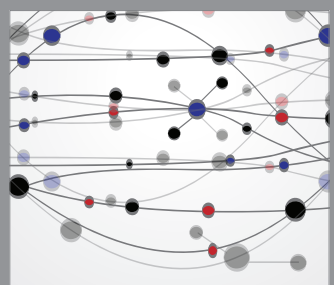

The Scientific World Journal
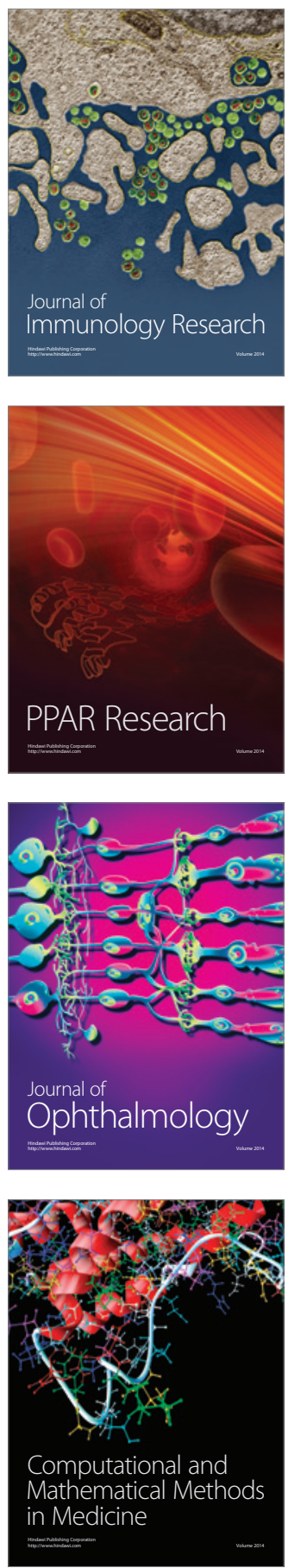

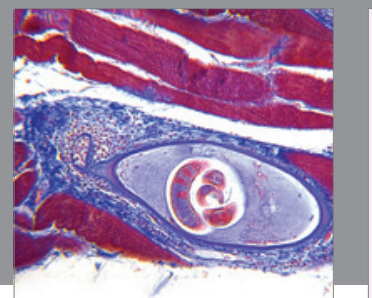

Gastroenterology

Research and Practice
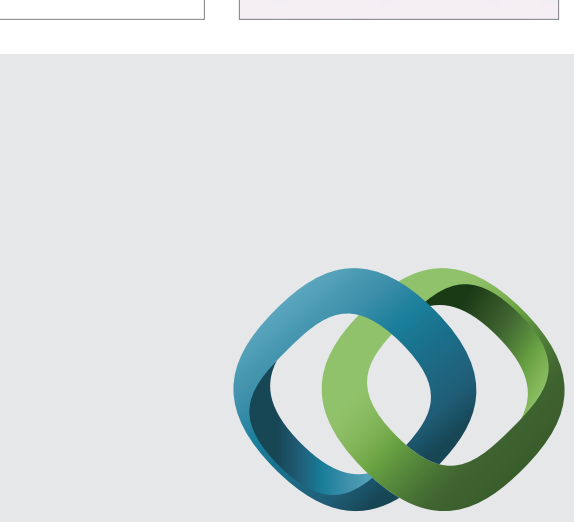

\section{Hindawi}

Submit your manuscripts at

http://www.hindawi.com
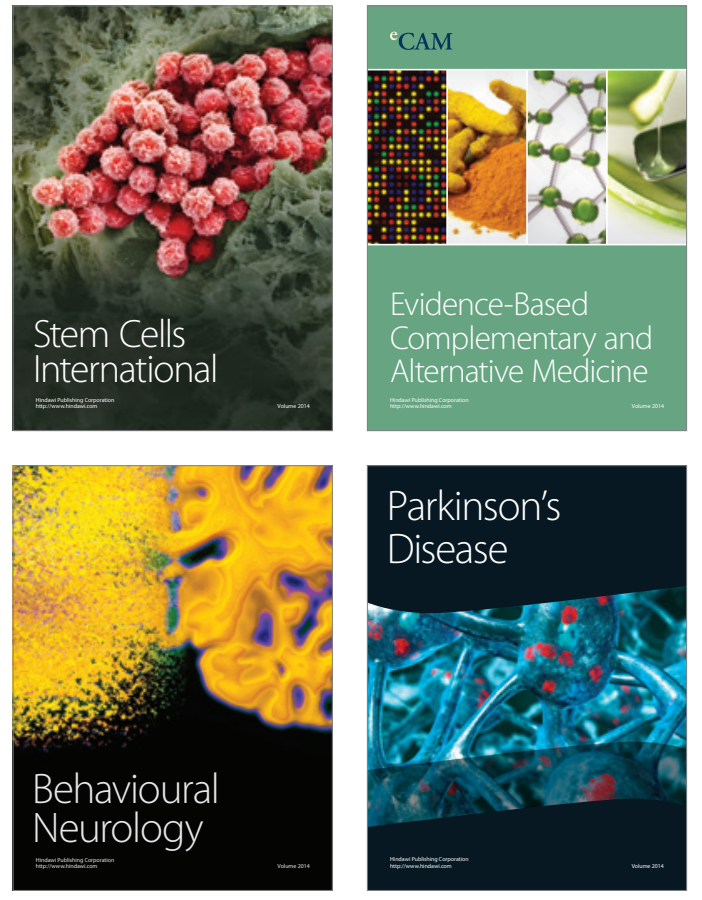
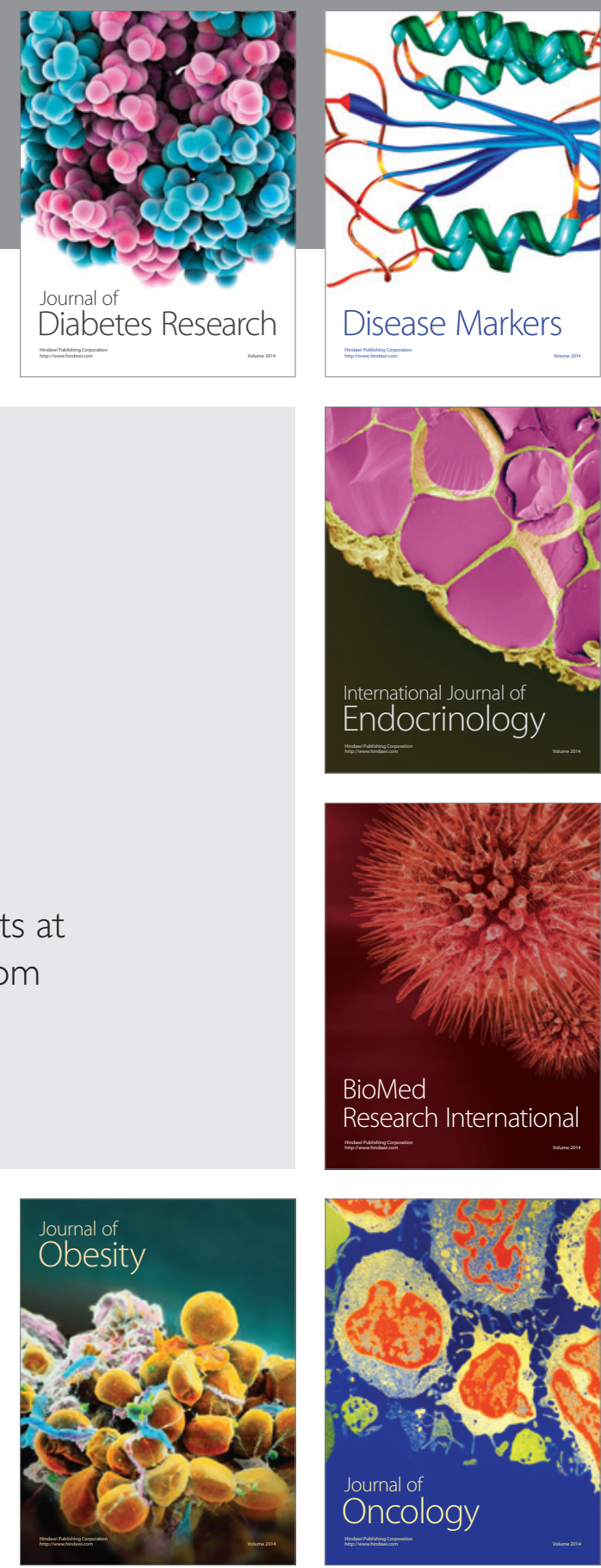

Disease Markers
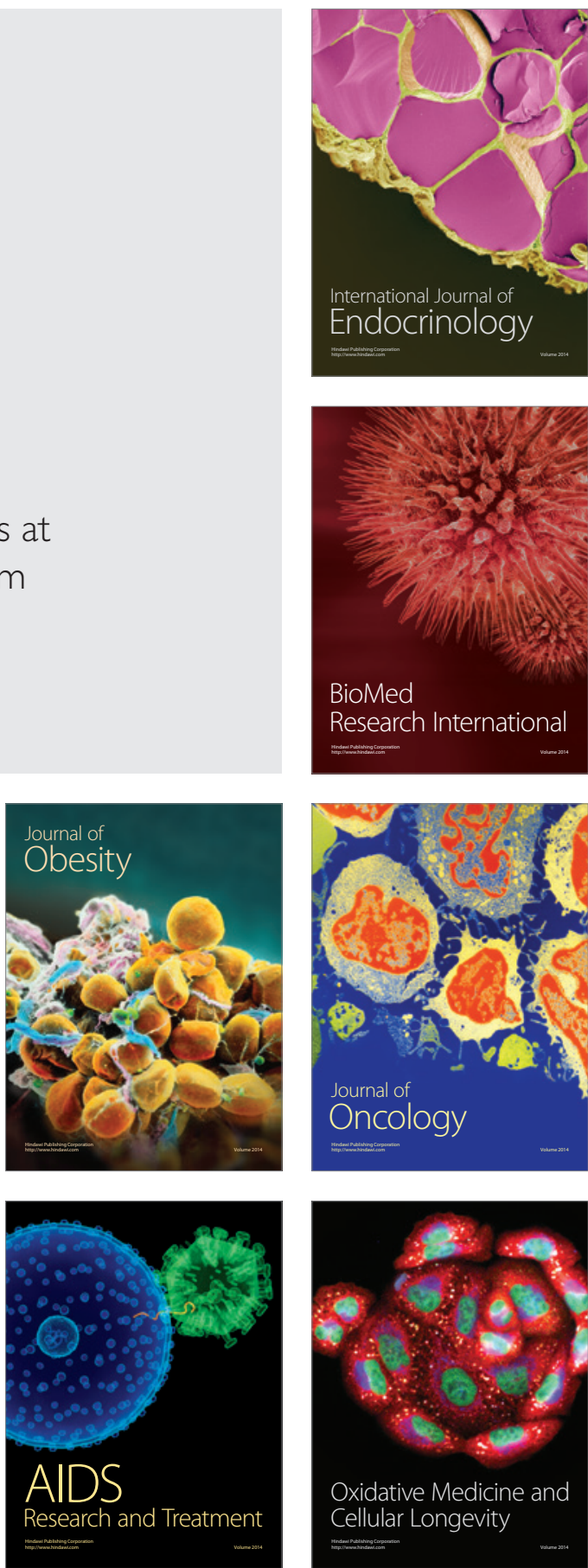